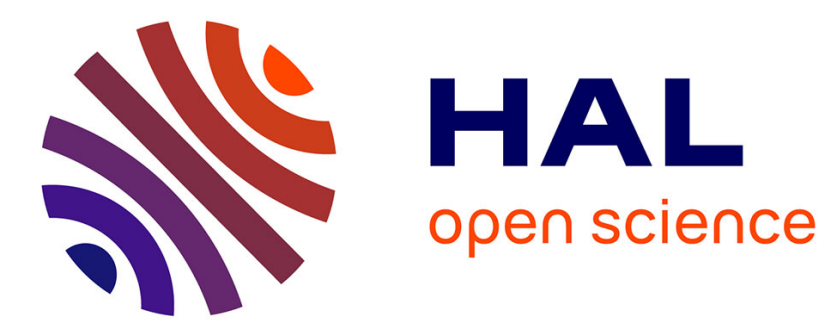

\title{
STUDY OF FRACTURE IN Cu-Al-Ni SHAPE MEMORY BICRYSTALS
}

S. Miyazaki, Tadashi Kawai, K. Otsuka

\section{To cite this version:}

S. Miyazaki, Tadashi Kawai, K. Otsuka. STUDY OF FRACTURE IN Cu-Al-Ni SHAPE MEMORY BICRYSTALS. Journal de Physique Colloques, 1982, 43 (C4), pp.C4-813-C4-818. 10.1051/jphyscol:19824133 . jpa-00222119

\section{HAL Id: jpa-00222119 https://hal.science/jpa-00222119}

Submitted on 1 Jan 1982

HAL is a multi-disciplinary open access archive for the deposit and dissemination of scientific research documents, whether they are published or not. The documents may come from teaching and research institutions in France or abroad, or from public or private research centers.
L'archive ouverte pluridisciplinaire HAL, est destinée au dépôt et à la diffusion de documents scientifiques de niveau recherche, publiés ou non, émanant des établissements d'enseignement et de recherche français ou étrangers, des laboratoires publics ou privés. 
JOURNAL DE PHYSIQUE

\title{
STUDY OF FRACTURE IN CU-Ai-Ni SHAPE MEMORY BICRYSTALS
}

S. Miyazaki, T. Kawai and K. Otsuka

Institute of Materials Science, University of Tsukuba, Sakura-mura, Tbarakiken 305, Japan

(Accepted 9 August 1982)

\begin{abstract}
The intergranular fracture in $\mathrm{Cu}$-based shape memory alloys is most hazardous for the application of these alloys. In order to clarify the cause of the fracture, the fracture behavior of several $\mathrm{Cu}-\mathrm{Al}-\mathrm{Ni}$ bicrystals with different orientation relationships have been examined by tensile tests. From these results, it has been shown that the cause of the intergranular fracture lies in the stress concentration at grain boundaries due to the large elastic anisotropy and/or due to the difference in transformation strain at the boundaries.
\end{abstract}

Introduction. - Among many shape memory alloys, $\mathrm{Cu}$-based $\mathrm{B}$ phase alloys are receiving most attention for commercial use because of reasons of economy. A serious problem in applying these alloys, however, is that the fracture stress and ductility of these alloys are low in the polycrystalline state because of their intergranular fracture. This brittleness was once suggested to be due to the large elastic anisotropy of $\beta$ phase alloys $(1,2)$. More recently the present authors reported that it would be the case, based on the result of the tensile tests of a few $\mathrm{Cu}-\mathrm{Al}-\mathrm{Ni}$ bicrystals (3). In order to justify the above proposition and to investigate another cause of the intergranular fracture of these alloys, the fracture behavior of other bicrystals with different orientation relationships have also been examined in the present study.

Experimental Procedure and Some Preliminary Considerations. - ( Specimens and tensile tests) The ingots of $\mathrm{Cu}-14.6 \mathrm{Al}-4.0 \mathrm{Ni}\left(\mathrm{wt} \frac{\mathrm{O}}{0}\right)$ and $\mathrm{Cu}-14.2 \mathrm{Al}-4.0 \mathrm{Ni}(\mathrm{wt} \%$ ) alloys in nominal composition were prepared from $99.99 \% \mathrm{Cu}, 99.99^{\circ} \mathrm{Al}$ and $99.9 \% \mathrm{Ni}$ by melting in a high frequency induction furnace followed by casting into an iron mold. The details of the specimen preparation have been reported elsewhere (3). The gauge length, width and thickness of the specimens were $5 \mathrm{~mm}, 2.5 \mathrm{~mm}$ and $1.5 \mathrm{~mm}$, respectively. ( See Fig. 1 of Ref.(3).) The tensile tests were carried out at a strain rate of $3.3 \times 10^{-4 / s}$ on an Instron-type tensile machine, Shimadzu Autograph DSS-10T -S type. The temperature during the tests were controlled by immersing specimens in either methanol cooled by liquid nitrogen or heated oil.

( Orientations of bicrystals and considerations of strain compatibility at a grain boundary) It was suggested in the previous paper that stress concentration at grain boundaries played an important role in both the initiation and propagation of cracks in polycrystalline Cu-based shape memory alloys (2). The stress concentration occurs at a grain boundary in order to make the strain components in each crystals compatible. Two types of strains are important in shape memory alloys, i.e. the elastic strain and the transformation strain. Preliminary considerations of the compatibility of these strains at the grain boundary is given in the following.

Each specimen used in this investigation has a grain boundary in the central portion, vertical to the tensile axis. The geometry of the bicrystals is shown in Fig. 1. For type of bicrystal shown in Fig. 1, the continuity of strain across the 
$X Y$ grain boundary is represented by the following relationships (4.5) :

$$
\varepsilon_{X X}^{A}=\varepsilon_{X X}^{B}, \varepsilon_{Y Y}^{A}=\varepsilon_{Y Y}^{B}, \varepsilon_{X Y}^{A}=\varepsilon_{X Y}^{B}
$$

Here the strain components on both sides represent the deformation of the boundary plane of the component crystals $A$ and $B$ respectively. When both crystals are in the elastic range, the degree of incompatibility at the boundary may be expressed conventionally by differences in the corresponding strain components as shown in the following :

$$
\begin{aligned}
& \Delta \varepsilon_{\mathrm{XX}}=\left|\varepsilon_{\mathrm{XX}^{-}}^{\mathrm{A}^{-}}-\varepsilon_{\mathrm{XX}^{-}}^{\mathrm{B}^{-}}\right| \\
& \Delta \varepsilon_{\mathrm{YY}}=\left|\varepsilon_{\mathrm{Y}^{-}}^{\mathrm{A}^{-}}-\varepsilon_{\mathrm{Y}^{-}}^{\mathrm{B}^{-}}\right| \\
& \Delta \varepsilon_{\mathrm{XY}}=\left|\varepsilon_{\mathrm{XY}}^{\mathrm{A}^{-}}-\varepsilon_{\mathrm{XY}^{-}}^{\mathrm{B}^{-}}\right|
\end{aligned}
$$

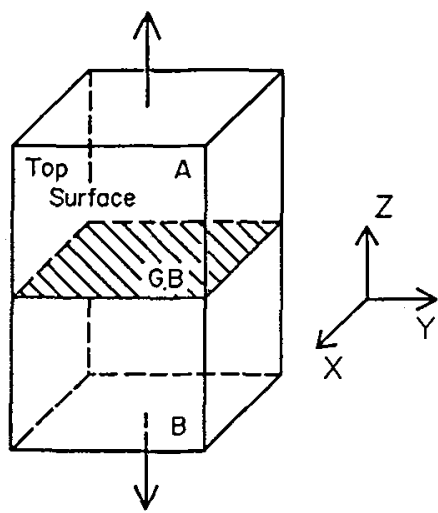

F1g. 1 Geometry of bicrystals used in the present tensile tests.

where the strain components $\varepsilon_{X X}^{A^{-}}, \varepsilon_{Y_{Y}^{-}}^{A^{-}}, \varepsilon_{X Y}^{A^{-}}$and $\varepsilon_{X X^{-}}^{B^{-}}, \varepsilon_{Y Y}^{B^{-}}, \varepsilon_{X Y}^{B^{-}}$represent the elastic strains of the component crystals $A$ and $B$, when they are deformed independently of each other as single crystals. In order to satisfy Eq. 1, the stress concentration is introduced at the grain boundary according to the value of these strain differences ( $\Delta \varepsilon_{X X}, \Delta \varepsilon_{Y Y}$ and $\Delta \varepsilon_{X Y}$ ), which increase with increasing elastic anisotropy of the component crystals. In an isotropic material, the strain differences at a grain boundary are obviously zero, so that stress concentration is absent at the boundary. In a highly anisotropic material, such as a Cu-Al-Ni alloy, the stress concentration is present at the grain boundary and the degree can be varied over a wide range by changing the relative orientations of the two component crystals. Therefore, it will be possible to show clearly the effect of the stress concentration at a grain boundary on the intergranular fracture, by utilizing bicrystals with various relative orientations.

When martensites are stress-induced, the transformation strain must also satisfy the compatibility condition of $\mathrm{Eq} .1$, if deformation proceeds without fracture. The transformation strain strongly depends on crystal orientation, and thus large stress concentrations may be induced at the grain boundary due to large differences in transformation strains in both component crystals (6) $(8)$.

Two kinds of bicrystal groups were used in this investigation. One type is a symmetric bicrystal, in which both component crystals ( A and B ) are oriented symmetrically with respect to the $X Y$ grain boundary plane and the tensile axis in each crystal is inclined at an angle of 10 or 20 degrees from a $<001>$ direction. Other types of bicrystals are random bicrystals, in which the component crystals are situated in random orientation to each othex. All the tensile axis and the top sur-

\begin{tabular}{|c|c|c|c|c|}
\hline & \multicolumn{2}{|c|}{ (A) } & \multicolumn{2}{|c|}{ (B) } \\
\hline & TENSILE AXIS & TOP SURFACE & TENSILE AXIS & TOP SURFACE \\
\hline RANDOM 1 & {$\left[\begin{array}{lll}0 & 62 & 79\end{array}\right]$} & $\left(\begin{array}{lll}1 & 0 & 0\end{array}\right)$ & {$\left[\begin{array}{lll}\overline{12} & 69 & 71\end{array}\right]$} & $(0 \overline{1} 1)$ \\
\hline RANDOM 2 & {$\left[\begin{array}{lll}10 & 19 & 20\end{array}\right]$} & $(59 \overline{5})$ & {$\left[\begin{array}{lll}26 & 4 \overline{7} & \overline{86}\end{array}\right]$} & $(0 \overline{87} 47)$ \\
\hline RANDOM 3 & [ $\left.\begin{array}{lll}0 & 28 & 41\end{array}\right]$ & $\left(\begin{array}{lll}1 & 0 & 0\end{array}\right)$ & {$\left[\begin{array}{llll}0 & 0 & 17 & 98\end{array}\right]$} & $\left(\begin{array}{lll}1 & 0 & 0\end{array}\right)$ \\
\hline RANDOM 4 & {$\left[\begin{array}{lll}1 & 1 & 11\end{array}\right]$} & $(\bar{I} \bar{I} 0)$ & {$\left[\begin{array}{lll}0 & \overline{12} & \overline{99}\end{array}\right]$} & $\left(\begin{array}{lll}1 & 0 & 0\end{array}\right)$ \\
\hline SYMMETRIC 1 & {$\left[\begin{array}{lll}0 & 17 & 98\end{array}\right]$} & $\left(\begin{array}{lll}1 & 0 & 0\end{array}\right)$ & {$\left[\begin{array}{llll}0 & 0 & 17 & 98\end{array}\right]$} & $\left(\begin{array}{lll}1 & 0 & 0\end{array}\right)$ \\
\hline SYMMETRIC 2 & {$\left[\begin{array}{lll}0 & 17 & 94\end{array}\right]$} & $\left(\begin{array}{lll}1 & 0 & 0\end{array}\right)$ & 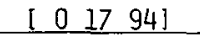 & $\left(\begin{array}{lll}1 & 0 & 0\end{array}\right)$ \\
\hline
\end{tabular}
faces of both component crystals $A$ and $B$ are shown in Table 1.

Table 1 Orientations of tensile axes and top surfaces of both component crystals $A$ and $B$. 
Results. - ( Case of random bicrystals ) In a random bicrystal the elastic strain differences defined by $\mathrm{Eq} .2$ are usually not simultaneously zero under stress. Thus stress concentration occurs at grain boundaries due to elastic anisotropy during elastic deformation. For a highly anisotropic material such as a Cu-Al-Ni alloy ( i.e. $A=2 c_{44} /\left(c_{1}-c_{12}\right) \cong 13(9)$ ), large and complex stress concentration is required to make all strain differences simultaneously zero in Eq. 2 . If no deformation mode is available at low stress levels in such a case, the stress concentration at the grain boundary becomes large enough to reach the fracture stress during elastic deformation at least macroscopically. Figure 2 shows the stress-strain curves in such a case. The curves (a) and (b) are those of random bicrystals (2) and (3) ( from here called RANDOM 2 and 3 ), respectively, in which the strain differences defined by Eq. 2 are not zero. The fracture occurred along grain boundaries during elastic deformation in these bicrystals and the fracture stresses were only about $100 \mathrm{MPa}$ and about $150 \mathrm{MPa}$, respectively. On the other hand RANDOM 1 , in which the strain difference in Eq. 2 is the largest of all bicrystals used in this investigation, showed intergranular fracture during quenching. The cause of the intergranular fracture in this case is considered to be due to the stress concentration at the grain boundary introduced by the thermal strain gradient from the specimen surface to the interior during quenching. The results of RANDOM 1 $\sim 3$ are consistent with the idea that the intergranular fracture is the result of high stress concentration at the grain boundary due to the large elastic anisotropy.

If the cause of the intergranular fracture is the stress concentration due to elastic anisotropy alone, a bicrystal without stress concentration due to such an effect would not fracture during elastic deformation. This can be tested by utilizing RANDOM 4, in which all three components of the elastic strain differences defined by Eq. 2 are simultaneously zero, but the transformation strains differ in the two component crystals. The stress-strain curve in this case is shown in Fig. 2(c), where fracture does not occur in the elastic region, but does after transformation at a stress level of about $300 \mathrm{MPa}$. The fracture in this case was an intergranular one. In order to clarify the cause of the intergranular fracture in this case, the same type of bicrystals with different compositions were tested at various temperatures, as shown in Fig. 3. Fracture does not occur during elastic deformation at any deformation temperature. The fracture stress is about the same as the critical stress for inducing

martensites in curves

(a) and (b). At higher temperature in (c) where martensites can not be induced by an applied stress, the specimen deformed a large amount by slip prior to fracture and the tensile strength was about $600 \mathrm{MPa}$. The value of the tensile strength is almost the same as that in a single crystal, as shown later. At temperatures lower than $M_{S}$, deformation modes such as twinning are available at low stress levels. Thus, a large strain is attained before fracture as shown by the curve (d), since the stress at the grain boundary is easily relaxed by these

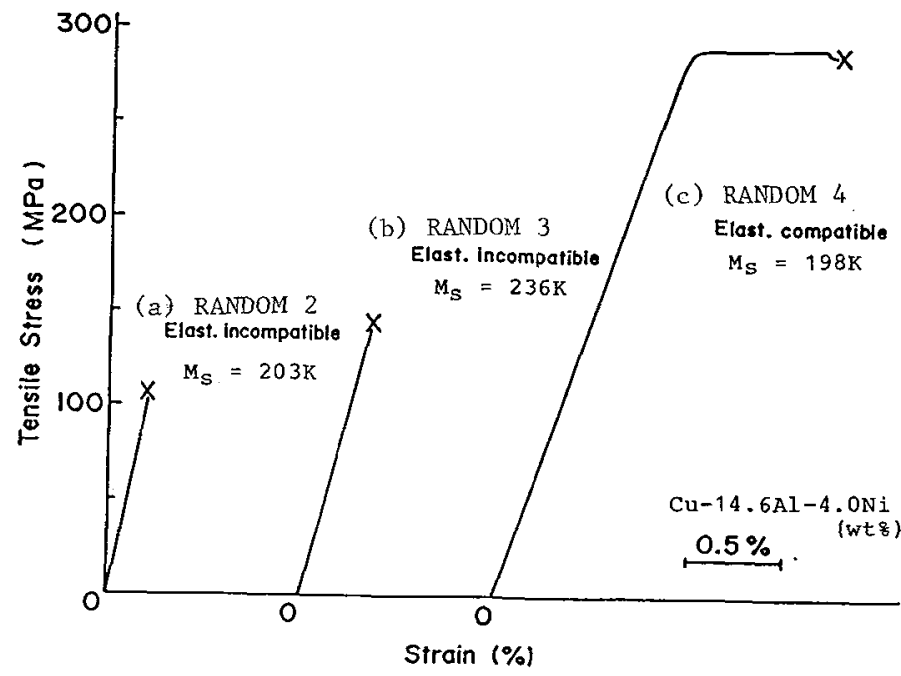

Fig. 2 The stress-strain curves of random bicrystals deformed at room temperature. The mark $(X)$ indicates the fracture points. 
deformation modes nearly until the variants are rearranged to only one preferred variant in each component crystal of the bicrystal. Fracture finally occurs at the grain boundary due to the difference of transformation strains. From these results, it is clear that the cause of the intergranular fracture in RANDOM 4 is the stress concentration at the boundary due to the incompatibility of transformation strains.

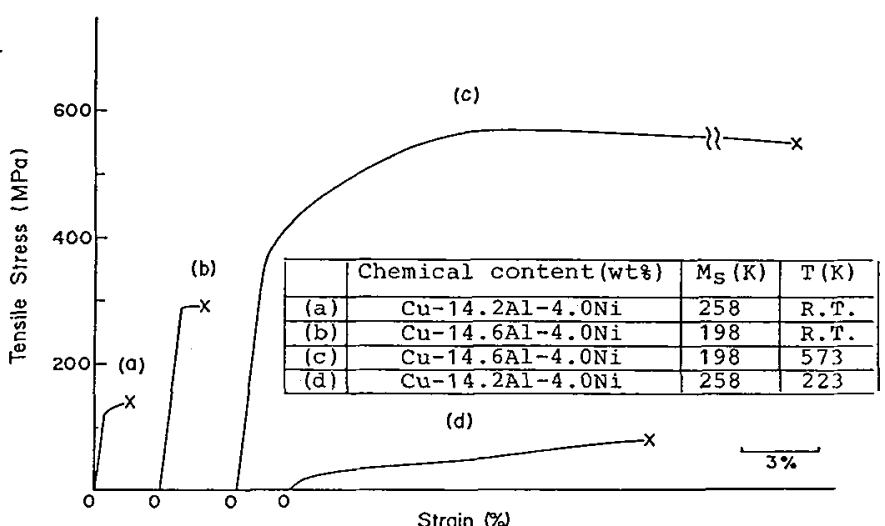

( Case of symmetric bicrystals ) As mentioned in the previous section,

if the cause of the intergranular fracture is the stress concentration at a grain boundary due to the large elastic anisotropy and/or due to the difference in transformation strains at the grain boundary, a symmetric bicrystal would deform like a single crystal. In the symmetric bicrystal (1) (from here called SYMMETRIC 1 ) martensites were stressinduced at the shoulder of the specimen and no martensite formed at the grain boundary at the initial stage of yielding (3). This is a clear indication that stress concentration is absent at the grain boundary, as confirmed by a calculation of the strain differences defined by Eq. 2. The stress-strain curves of SYMMETRIC 1 and 2 are shown in Fig. 4.

SYMMETRIC 1, for example, was loaded to more than 600 $\mathrm{MPa}$ until fracture occured.

The behavior is essentially the same as that of a single crystal which has the same orientation with one component crystal of the bicrystal, as

Fig. 3 Effect of composition and deformation temperature on the stress-strain curves in random bicrystal 4. ( Please note that the measurement of plastic strains is not accurate, since the strains at the shoulder parts of specimens outside of gauge length also contribute to the total strain in the present short tensile specimens.)

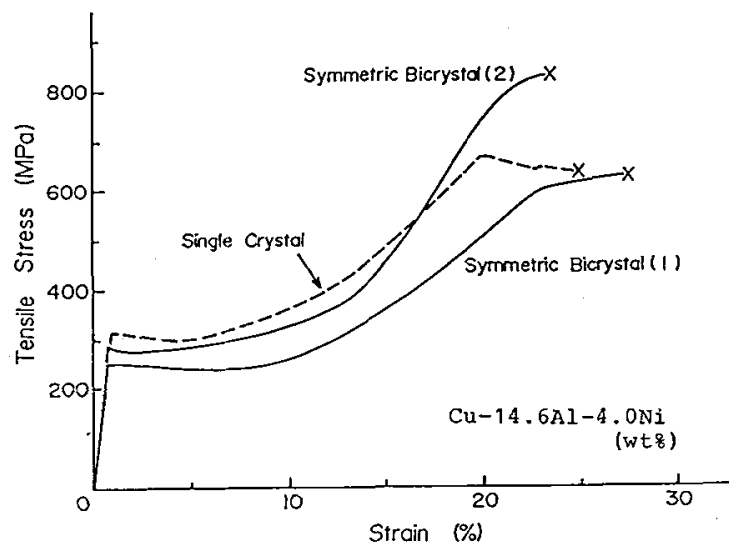

Fig. 4 The stress-strain curves of symmetric bicrystals 1 and 2 (in solid line) and that of a single crystal (in broken line) deformed at room temperature. The mark (X) indicates the fracture point. The $M_{S}$ and test temperatures of the bicrystals were $197 \mathrm{~K}$ and $294 \mathrm{~K}$, while those of the single crystal were $193 \mathrm{~K}$ and $296 \mathrm{~K}$, respectively.

indicated by a dotted line in Fig. 4. A clear transgranular fracture was observed in both SYMMETRIC 1 and 2. The fracture stresses of the two bicrystals are quite different. This tendency is essentially the same as that for single crystals, in which the fracture stress has a strong orientation dependence. The above facts are clear evidence to show that intergranular fracture in the $\mathrm{Cu}-\mathrm{Al}-\mathrm{Ni}$ alloy is caused by the brittleness of the boundary itself due to the presence of a secondary phase. 


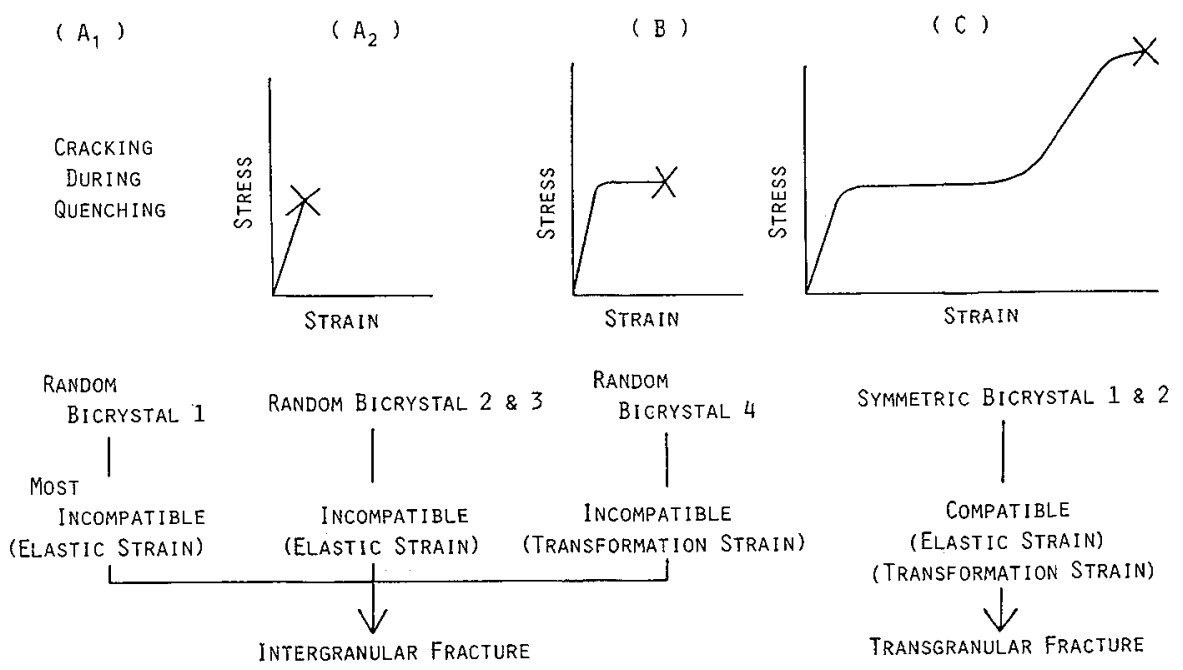

Fig. 5 The shematic stress-strain curves and fracture modes in $\mathrm{Cu}-\mathrm{Al}-\mathrm{Ni}$ bicrystals.

Concluding Remarks. - According to the above investigations, the fracture of $\mathrm{Cu}-\mathrm{Al}-\mathrm{Ni}$ shape memory alloys may be classified into three types ( $\mathrm{A}, \mathrm{B}$ and $\mathrm{C}$ ) as shown in Fig. 5, depending upon the compatibility condition of the boundary,

Type A: The boundary is elastically incompatible. The fracture occurs in the elastic region ( at least macroscopically) along the grain boundary (RANDOM 2 and 3). If the degree of incompatibility is very large, the fracture occurs along the grain boundary during quenching, because of the large stress concentration at the grain boundary due to large thermal gradient (RANDOM 1).

Type B : The boundary is elastically compatible, but plastically incompatible. The fracture occurs along the grain boundary after maxtensites are stress-induced. Thus the fracture occurs in the first stage of the stress-strain curve (RANDOM 4).

Type C : When a bicrystal is symmetric, the boundary is compatible both elastically and plastically*. Since no stress is concentrated at the boundary, fracture occurs in a transgranular manner. In this case the deformation and fracture behavior are essentially the same as those of one of the component crystals ( SYMMETRIC 1 and 2 ).

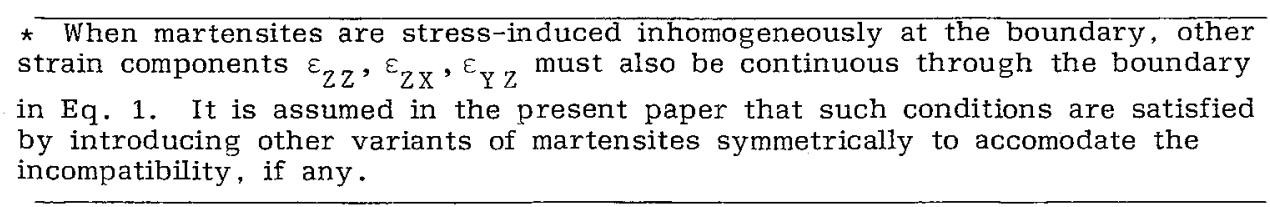

From the results obtained in this investigation it may be concluded that the cause of the intergranular fracture in the present alloy and other $\beta$ phase alloys is stress concentration at the grain boundaries due to the large elastic anisotropy and/ox due to the difference of transformation strains at the grain boundaries, and not due to the brittleness of boundaries themselves due to the presence of a secondary phase. Thus, from the above conclusion it is suggested that the brittleness of $\mathrm{Cu}$-based shape memory alloys may be improved by giving them a certain texture to suppress the stress concentration at grain boundaries. It is also understood by the above conclusion that one of the causes of ductility in the polycrystalline $\mathrm{Ti}-\mathrm{Ni}$ alloy is the small elastic anisotropy of this alloy $(\mathrm{A}=2$ $(10) \sim(12))$. 
Acknowledgment. - The authors would like to express sincere appreciation to Professor K.Shimizu and Mr.H.Sakamoto at Osaka University, and to Professor J.Takamura at Kyoto University for useful discussions.

\section{References}

(1) MELTON,K.N. and MERCIER,O., Acta Met. 27 (1979) 137.

(2) MIYAZAKI,S., OTSUKA,K., SAKAMOTO,H. and SHIMIZU,K., Trans. Japan Inst. Metals 22 (1981) 244.

(3) MIYAZAKI, $\bar{S}$., KAWAI, T. and OTSUKA, K. Scripta Met. 16 (1982) 431

(4) LIVINGSTON, J.D. and CHALMERS, B., Acta Met. 5 (1957) 322.

(5) HOOK,R.E. and HIRTH,J.P., Acta Met. 15 (1967) 535, 1099.

(6) OTSUKA, K. and SHIMIZU,K., Trans. Japan Inst. Metals 15 (1974) 103.

(7) SAKAMOTO,H., KIZIMA, Y. and SHIMIZU, K., Annual Meeting of the Japan Inst. of Metals (1981).

(8) SABURI,T and NENNO, S., to be published in Proceeding of International Conference on Solid-solid Phase Transformations, Pittsburgh, 1981.

(9) SUEZAWA,M. and SUMINO,K., Scripta Met. 10 (1976) 789.

(10) MIYAZAKI, S., OTSUKA, K, and SUZUKI, Y. Scripta Met. 15 (1981) 287

(11) MIYAZAKI, S. and OTSUKA,K., Sci. Rep. Res. Inst. Tohoku Univ. $\underline{A} 29$ Suppl. 1 (1981) 111.

(12) MERCieR,o., MELTON,K.N., GREMAND,G. and HAGI,J., J. Appl. Phys. 51 (1980) 1833 . 